\title{
Detrivialization as a Strategy to Challenge Organizational Groupthink
}

\author{
Salaheddine Mnasri and Stavros Papakonstantinidis \\ The American University of the Middle East \\ Slaheddine.Mnasri@aum.edu.kw \\ Stavros.Papakonstantinidis@aum.edu.kw \\ DOI: 10.34190/EJKM.18.03.003
}

\begin{abstract}
This paper aims to contribute to the literature on knowledge construction and knowledge sharing within the field of organizational communication. The research underlines the importance of exploring human learning contextually, descriptively, interpretively, and inductively. Through a participant-observer methodological approach, the study contributes to the literature by introducing detrivialization as a strategy to explore 'participants' rhetoric related to their organizational procedures. The paper describes a case study that took place for 18 months in a cancer research lab in Belgium, where employees seemed unable to question several taken-for-granted practices. The present research primarily reveals the consequences of trivialization, when the rationale of essential organizational practices go unnoticed until observerparticipant challenges the status quo. Also, the study highlights the outcomes of the detrivialization approach, which triggers unprecedented knowledge. Finally, the paper introduces the (de)trivialization dynamic model, which can depict the consequences of opening black-boxes in organizational contexts. This research is a new approach in organizational ethnomethodology, revisiting 'Garfinkel's (1967) breaching experiment to describe science in action. The suggested model offers a methodological approach for exploring trivialized organizational dynamics and challenging groupthink. Detrivialization is an opposite approach to trivialization, to offer a new debate topic to scholars aiming to conduct ethnographic research and discourse analysis in organizational communication.
\end{abstract}

Keywords: Detrivialization, knowledge construction, knowledge sharing, groupthink, discourse analysis, organizational culture, organizational communication.

\section{Introduction}

How do we know what we know? This fundamental question functions as the basis for knowledge construction. The present paper calls attention to trivialization practices within organizations as a strategy to examine how employees make meaning and share collective knowledge in organizational contexts. In organizations, as in any social setting, trivialization practices go unnoticed to the extent that employees follow them unquestionably and fall into groupthink (Carlson, 2016; Kuhn, 2014; Hällgren, 2010; Mpeera Ntayi et al., 2010; Garfinkel, 2002; Latour 2005; Simon et al., 1995; Kroon et al., 1991; Whyte, 1989; Latour, 1987; Janis, 1982; Latour \& Woolgar, 1979; Janis 1971; and Festinger, 1962). In the same pursuit, the present research inductively identified a case where employees trivialize pieces of information to the extent that groupthink occurs over issues that they paradoxically consider to be of great importance. What outcomes could such practices generate in the context of knowledge construction? What happens if people identify and question trivialized organizational practices?

Kuhn (2014) argues that the study of knowledge construction from an organizational communication perspective is gaining an increasing interest. This research is part of a global academic pursuit regarding "what is learning or what makes knowing?" The authors suggest that studying trivialization practices as such can be an effective strategy to understand the unexplored aspects of organizational knowledge and to avoid groupthink. By triviality, we mean the "lack of seriousness or importance; insignificance," and by trivial, we refer to something "of little value or importance" (Trvial, Oxford dictionaries, 2018). To trivialize means to "make (something) seem less important, significant, or complex than it is.

Knowledge creation and sharing are discussed in the literature. The organizational behavior factors of organizational culture, job performance, and knowledge sharing lead to job satisfaction. Kucharska and Bedford (2019) argue that to optimize company performance and increase job satisfaction, organizations should enhance knowledge sharing. Evans et al. (2019) suggest a two-way method to examine knowledge sharing. The authors argue that research should first explore the usefulness of shared knowledge, and second, the participants' willingness to communicate that knowledge. Through surveying legal professionals at a large Canadian firm, the latter study revealed that organizational ties, competence, integrity, and trust have a substantial impact on 
sharing tacit knowledge. Kyakulumbye et al. (2019) explain that social interactions construct and share tacit knowledge in organizational settings.

People say that the devil lies in the details when they explain the importance of accurate information in knowledge construction. Sometimes employees fail to notice the rationale of their daily work routines, considering some practices and pieces of information as trivial. Furthermore, when this situation occurs in scientific research labs, it may have more serious consequences. Research findings may unnoticeably and avoidably be skewed. Therefore, the authors adopt a participant-observer ethnographic approach to explore the views and rhetorics of researchers about trivialization practices in a cancer research lab. Following an ethnographic approach, the others examined the inextricable relationship between human communication and knowledge construction through a case study of a cancer research lab in Belgium.

The authors use a pertinent case study, a learning organization and focus on some practices of trivialization, aiming at understanding their underlying dynamic. They studied the organizational dynamics caused by trivialization practices as a strategic entry point to explore aspects of the learning or collective knowledge construction. Through a case study, the authors identify and explore some trivialization practices that emerge in interactions as key and unique moments in the knowledge construction dynamic. We suppose that if we capture and study those moments where people (scientists in the case of the present research) trivialize matters, we can gain insights into what they collectively assume, how they make choices and drop others, and how they prioritize matters and play down others, etc. More particularly, the research pays attention to whether our scientists trivialize matters systematically or sporadically, noticeably or inadvertently, and most importantly: can they rationalize their choices? We assume that such a pursuit could constitute a new strategy to observe knowledge construction in situ (scientists in a research lab). Therefore, this paper has two objectives. The first objective is to examine how trivialization occurs in organizational communication, to focus on the outcomes within the broader learning dynamic. The second objective is to suggest an organizational communication model of reverse trivialization. For this reason, we introduce the term detrivialization as a neologism to refer to the reversal of trivialization. We are using detrivialization as a strategy to explore what our scientists have 'silently' taken-for-granted.

The next section builds on the existing literature to include past research findings reporting how people in organizations can distort or compromise scientific knowledge. This paper aims to inquire about the usefulness of studying trivialization to explore knowledge construction in organizational communication.

\section{Literature review}

Groupthink is a well-established concept in social psychology and communication. Groupthink refers to an illusion of agreement and to an excess of group cohesiveness, which causes limitations to knowledge building (Beebe and Masterson, 2014). Hallgren (2010, p.97) writes that "groupthink behavior is associated with people retaining the status quo by minimizing their conflicts without critical assessment, analysis, and evaluation." A group experiences groupthink when it meets three conditions: overconfidence, closed-mindedness, and pressure towards conformity (Manz and Neck, 1997).

Whyte (1952) was the first scholar to use the term groupthink, but Janis (1971) researched within the theoretical framework of social psychology. Janis (1982) argues that groupthink is a concurrence-seeking tendency that relates to cohesiveness, structure, and context. Janis (1971, p. 43) establishes the relationship between groupthink and trivialization “in the spirit of Parkinson's law [...] the more amiability and esprit de corps there is among the members of a policy-making ingroup, the greater the danger that independent critical thinking will be replaced by groupthink, which is likely to result in irrational and dehumanizing actions." Parkinson's Law of Triviality (Parkinson, 1958) also addresses the connection between groupthink and ambiguity in knowledge construction.

Although the term groupthink was primarily discussed by Whyte (1952), the literature remains limited to understand how groupthink affects knowledge sharing (Carlson, 2016). Koerber and Neck (2003) revisited Whyte's groupthink framework to analyze several resignation decisions in the Major League Umpires Association. The latter authors underline the relationship between groupthink and defective decision making. Also, Ben-Hur et al. (2012) suggest that the organizational context affects knowledge sharing and decision making. On the same wavelength, Kroon et al. (1991) argue that the realization and reduction of groupthink in 
organizations, lower collective avoidance, and increase individual accountability. Mpeera Ntayi et al. (2010) and Eaton (2001) confirm the strong relationship between social cohesion, groupthink, concurrence-seeking, and ethical attitudes among employees as significant factors of ethical behavior. Studies on groupthink show that group over-cohesiveness causes defective decision making (Sai On Ko, 2005), while over-reliance on collective organizational trust can impact negatively on performance (Erdem, 2003).

In the present case study, once we identify instances of trivializations in the cancer research lab, we question them. We are not content with "clear cut" answers that are usually solicited by structured questionnaires. Instead, we explore these trivializations by opening detailed discussions with the lab members. We also aim to compare and contrast the different responses and accounts, because if the lab members happen to be avoiding controversies, we may not be able to understand the complexity of the trivialized issue.

As a psychological phenomenon, scholars who ask open-ended questions can recognize groupthink within real meeting dialogues over trivialized issues (Eisenberg et al. 2010). This research suggests detrivialization as a method to explore existing knowledge. Eisenberg et al. (2010, p.46) distinguish among four types of dialogues: the mindful communication dialogue, the equitable transaction dialogue, the empathic dialogue, and the real meeting dialogue. The latter authors emphasize the need for the real-meeting dialogue in learning because it is "not merely for the purpose of exchanging ideas or information in order to learn, it is engaged in for the purpose of revising how the parties involved actually understand something."

Although the empathetic dialogue can be essential in achieving cohesion, harmony, and understanding between group members within organizations, the real meeting dialogue "involves far more than simply getting someone's "take" on a situation for the sake of information; it involves being open to changing an opinion as the result of soliciting the perspective of another" (Eisenberg et al. 2010, p.46). To avoid empathizing with others at the expense of being authentic (e.g., being able to say what we think and not what others want to hear), real meeting dialogues lead to new and better ways of organizational practices. Daring to rethink what has otherwise been trivialized or taken for granted is that crucial moment where we shift from an empathetic to a real meeting dialogue (Garfinkel, 2002).

Trivialization is another socio-psychological phenomenon that this research examines. Within the framework of the Sociology of Scientific Knowledge (SSK), scholars have emphasized the importance of focusing on triviality and trivialization in scientific contexts (Kuhn, 2014; Latour 2005; Latour \& Woolgar, 1979). Through observation of a biology lab, Latour \& Woolgar (1979, p. 274) reported that what interested them as sociologists was described by the biologists (their own participants) to be "unsurprising if not trivial" and that such "reaction was a nice confirmation of the accuracy of our [their] observations."

Moreover, Latour and Woolgar (1979, p. 154) offer examples of how "facts can be created and destroyed during brief conversational exchanges." The latter authors argue that group members face difficulty contradicting one another to avoid controversies at the expense of accuracy. Latour \& Woolgar (1979, p. 243) write "the standing of one scientist might be such that when he defines a problem as important, no one feels able to object that it is a trivial question."

Building on the fundamental research of Latour \& Woolgar (1979), the current paper's authors aimed at following scientists in their habitat to explore their knowledge construction on the go; i.e., before packaging. Latour (2005) argues on the need to open "Pandora's black box,"; i.e., urging scientists to engage in thoughts and discussions about how otherwise taken-for-granted things actually work inside (example machines) and not just to assume that they are working correctly. Latour (2005) stresses the need to follow scientists during their construction of knowledge (in situ), not when they present their 'nicely packaged' findings.

After observing people at work, "reality was the consequence of the settlement of a dispute rather than its cause" (Latour \& Woolgar, 1979, p. 236). The latter authors mention that the lab members avoided disagreements at the expense of scientific accuracy, regardless of the consequences of compromising knowledge building. Based on these findings, Latour and Woolgar (1979) stress the importance of distinguishing between what is scientific and what is not in the scientists' discourse.

At the individual level, socio-psychological studies have described in different ways the psychological hassle that an individual can experience. Simon et al. (1995) conducted four separate studies and concluded that their 
participants use trivialization (reduction) when they face the psychological pressure of cognitive dissonance (being seen as contradictory). Rather than changing of opinion or admitting the contradiction, participants played down the importance of disagreement.

Other studies illustrate that people do not want to be seen as contradictory or inconsistent because they suffer from mental stress (Festinger, 1962). In the present case study, we examine how individuals in a cancer research lab would argue when contradictions would be pointed out. Also, the authors examined to what extent participants were compromising knowledge to avoid talking inconsistently. Finally, building on several scholars' research (Kuhn, 2014; Garfinkel, 2002; Whyte, 1989; Janis, 1982; Latour and Woolgar, 1979), the present paper argues that observing how people interact at work helps at understanding how knowledge is being constructed. This paper's authors argue that: a) trivialization can potentially hinder knowledge building and that b) studying detrivialization can be a good strategy to gain insights on knowing.

After defining triviality and building on Latour's work (1979, 1987, and 2005), the paper explores how trivialization would function within a cancer research lab. Using Callon's (1986) translation theory model, the authors enquire how to trace back knowledge building over long-established trivialized ideas and how to distinguish between the scientific and non-scientific constructs. The next section explains the methodology that this research follows.

\section{Methodology}

Discursive psychology forms the theoretical and methodological framework of this paper. The research hinges on Potter's and Wetherell's (1987) discursive psychology assumptions. The latter authors argue that knowledge is a discourse activity, and studying how people construct knowledge can be achieved through the analysis of the discourse practices in all their forms. We decided to adopt discursive psychology as our framework for two reasons:

1. discursive psychology is a discourse analysis method oriented into socio-psychological factors and is therefore well-positioned to study knowledge construction issues (i.e., trivialization, individual and group practices, learning organizations) (Potter and Wetherell, 1987);

2. discursive psychology is effective in analyzing scientific discourse since our data is scientific (cancer research data, collected through observation and interviews). Because "discourse" applies in a variety of interpretations across disciplines such as linguistics, psychology, anthropology, literary studies, philosophy, and communication studies, in the present study we use the term to mean "all forms of spoken interaction, formal and informal, and written texts of all kinds" (Potter and Wetherell, 1987, p. 8).

The present research aims at exploring the trivialization practices in a cancer research lab in Belgium. The study seeks to understand the covert and overt dimensions of sharing trivialized scientific information and how such an organizational communication dynamic relates to knowledge construction. This paper's authors adopted a participant-observer methodological approach to understand how employees were sharing scientific knowledge and identify which information seemed to be trivialized to their work routines.

The study follows a similar methodological approach, as developed by Latour and Woolgar (1979), who describe their research as "microprocessing of facts." After conducting a longitudinal observation within a biology lab in the US, Latour and Woolgar (1979) provided details on how people constructed scientific facts. The latter authors scrutinized moments where the biology lab scientists took decisions and made choices in a somewhat unexpected way. Many times, scientific facts were "born" (when proved by scientists) and "destroyed" (when rejected as wrong). The same study showed that sometimes an odd set of accidental circumstances dictated the scientists' decisions, unnoticeably. Hence, specific scientific facts, no matter how well-established they could be, were seen by the lab scientists as [as]sociologically (rather than logically) determined (Latour and Woolgar, 1979).

This study aims at exploring three main questions: a) how trivialization practices construct organizational knowledge; b) how organizational knowledge emerges through detrivialization approaches, and c) how ethnomethodology and discourse analysis could be useful in understanding aspects of knowledge building. The study suggests the exploration of the (de)trivialization dynamic in terms of three research levels: 
(inter)organizational, individual, and group following the chronological sequencing that we undertook: observation, individual, and then group interviewing.

The research presupposes that trivialization is a practice that exists in cancer research labs, as in any other social context (Eisenberg et al. 2010; Whyte, 1989; Janis, 1982; Latour and Woolgar, 1979). From a broader philosophical perspective, our research addresses Feyerabend's (1978) concern regarding the dogmatic and sectarian practices of modern sciences. One of the paper's authors conducted the field research as participantobserver at a cancer research lab in Brussels, Belgium. The observation period lasted 18 months with sporadic absences. Through this period, the field researcher was able to access the lab daily. The field researcher received permission to access any area in the lab and speak to all stakeholders.

After gathering several contradictions and inconsistencies for this case, during the observation stage, we conducted semi-structured tape-recorded individual interviews with the ten lab members, which we analyzed synchronically. Approximately six months later, we conducted collective tape-recorded interviews questioning the same issue with the lab members, which we analyzed diachronically. We used Potter's and Wetherell's (1987) methodological tools to analyze our findings.

Using the data that we collected from the individual interviews, we identified several variations of accounts across persons and some inconsistencies made by the same person during the same interview. We detailed where 'scientific knowledge' is interwoven with ungrounded knowledge: 'common sense' and 'value judgments.' We also identified how individuals' accounts and positions regarding the issues (previously trivialized) were developing on the move about our questions or to how the ongoing discussions were progressing. This method helped us identify discourse strategies used to avoid dissonance. Hence the detrivialization prompted by our research triggered new accounts and positions, which have research implications.

The diachronic and collective interviews helped us identify the same variations and controversies as examined synchronically and individually. The intermingling between 'scientifically grounded knowledge' and the 'common sense' and 'value judgments' that emerged during the synchronic interviews persisted in the diachronic conversations, and the ungrounded trivialization practices in discourse grew stronger. Hence, depending on our questions, the participants oscillated recursively and restlessly between trivializing and detrivializing positions. We outlined dissonance avoidance (Festinger, 1962) strategies used by the participants to bypass controversies without settling them.

Following the same steps of fieldwork research, as Garfinkel (1967) explained in his breaching experiment, the study's field researcher adhered to the lab's safety rules and explained to participants the central role that anonymity and confidentiality play in social sciences research. The field researcher requested for participant's formal consent to participate in the study by assuring them that anonymity is guaranteed. Therefore, all names mentioned in this paper are not real to ensure that no one can trace back and link the people with the data they provide.

The study's participants were ten lab members: the principal investigator, four postdoctoral researchers, two doctoral researchers, two technicians, and one intern. Except for the intern, all the members have considerable experience in cancer research labs (from 7 to 25 years). Two of them are Belgians; the others are from different nationalities: Dutch, French, Spanish. Except for one technician, all of them have international experience either in Paris or in the USA. The lab director and founder pursued his graduate and postgraduate studies at universities in the USA.

To support the lab staff's scientific competence, we visited the lab's website to read people's bios. The director is involved in the publication of 217 research articles; 30 of them also include the names of the postdoctoral researchers. The same website lists 17 reviews, dated from 2002 to 2017, each of them is of multiple authors (usually 3, but a couple of them have 5 and 6 authors). Finally, the lab staff has published nine scientific books between 1995 and 2012. The next section introduces the case study and explains in chronological order some critical discussions between the field researcher and the participants that lead to knowledge creation.

\subsection{Case Study: The incubator's $\mathrm{CO}_{2}$ level for cell culture}

The case study below is a narrative written in the first person to highlight the field 'researcher's first-hand experience with ethnographic research. Hence, the case study aims to bring the reader closer to the lab's 
experience and demonstrate the levels of familiarity and openness between the field researcher and the lab scientists.

During my first weeks in the lab, I walked into the culture room and found Sophie, Stephan, and Marie (all names are given by the authors to maintain anonymity and assure confidentiality). Sophie is a medical doctor and had worked as a physician in hospitals for six years before joining the lab. When I faced an incubator, I noticed that it displayed the following two figures: $5 \% \mathrm{CO}_{2}$ and $37^{\circ} \mathrm{C}$. I assumed that $37^{\circ} \mathrm{C}$ is the appropriate temperature to maintain the cells as in a healthy human body. But why is $5 \%$ the appropriate level for $\mathrm{CO}_{2}$ ? I was trying to see how the gas tank was linked to the incubator, assuming that it was there to automatically feed it with the quantity of $\mathrm{CO}_{2}$ each time the pressure within the incubator drops.

Sophie, who had been willing to explain things to me, looked at me and said in French: "that's for $\mathrm{CO}_{2}$ ". $\mathrm{My}$ follow up question was: "Why do these cells in the incubator need $\mathrm{CO}_{2}$ ?". The response was, "as in our body." I said, "but why $5 \%$ ?". When I said that, she looked away and I felt that the mood changed in the room, but could not tell what was wrong. I moved next to Stephan, who listened to the discussion and was usually willing to talk. Stephan's response also demonstrated some ignorance in providing us with an answer, as it seemed to him a trivialized matter. I decided not to insist on asking to follow up questions to avoid disturbing anyone.

A few minutes later, Sophie asked Stephan, who said: "I have no clue why 5\%". Then, I deduced that the silence in the room has something to do with my question, and possibly they were trying to find an answer to the question. Then, Sophie looked at me and said in French, "it's shameful." I said, "what is shameful?"; she said that they didn't know why the incubator is regulated at 5\%. I told her, "but no one knows everything." Sophie said, "yes, but this is important." I later realized why Sophie was upset about the fact that she does not know the answer. Being a physician, she probably thought that she should have known how much $\mathrm{CO}_{2}$ the human body needs.

This $\mathrm{CO}_{2}$ indicator proved to be a trivialized issue that lab scientists were observing unquestionably. I asked several people in the lab about the $\mathrm{CO}_{2}$ indicator, including the three post-doctoral researchers, two technicians in the culture room, and an intern. The responses to my questions were like the following: "I don't know," "I have no clue," "ah, that's a good question, but I don't have an answer, right now," but whenever I kept the discussion going the lab scientists responded in a rather similar fashion. Some participants aimed to justify an answer, but they lacked scientific proof. "I don't know, but it is important for the equilibrium of the cells," "it's to maintain the cells in good condition," "it's important for the phenotype." All participants seemed to provide me with confusing and sometimes off-topic explanations. On the first day where this issue was identified, none of the lab members was able to explain why the incubator is regulated at $5 \%$.

After searching online for relevant answers to the question about the $\mathrm{CO}_{2}$ indicator, I found that no matter what the exact answer was, the $\mathrm{CO}_{2}$ was said to be used in the incubators to maintain the acidity or the $\mathrm{pH}$ level in the medium, where the cells are cultivated. The next day, I discussed with everyone I came across, and many of them provided me with the same answer that I found online. I started to hear things such as, "yeah, that's normal because, without $\mathrm{CO}_{2}$, the $\mathrm{pH}$ level would drop," "yeah, it's related to the acidity of the medium." Knowing the source of their answers, I pushed for further discussions by asking, "ok, but why $5 \%$ in particular?" and "who decided that?". At this level, all of them said in a way or another that it was tested in the past and that was part of the basics that research at this level should not rebut.

Discussions started to become interesting for both sides. Certain lab scientists showed great interest in discussing with me. A trivialized matter that was taken for granted had become a topic of general interest and discussion. People seemed to agree that the matter was " related to the ph level," my question evolved into why $5 \%$ in particular and not more or less? The main question evolved into several other sub-questions, such as, "does the human body also have $5 \%$ of $\mathrm{CO}_{2}$ ?" and "are there other side effects that could happen to the cells if the $5 \%$ is not the best choice?"

After a couple of months of discussions over similar issues of trivialized organizational procedures, the general feeling was that many matters were taken for granted without any of the experts in the lab trying to challenge the status quo. Lab scientists were relying on each others' knowledge. It was a unique case, where I could experience and observe discussions over issues that were initially said to be either trivialized or unknown and to explore how organizational knowledge could be constructed in discourse. Although we discussed several 
matters during my field observation, the authors of this paper find the case of the incubator's $\mathrm{CO}_{2}$ level for cell culture to be unique and representative of how organizational knowledge could be constructed. Therefore, we decided to conduct tape-recorded follow-up interviews with the lab scientists over the issue of the $\mathrm{CO}_{2}$ level in the incubator.

We designed a semi-structured interview, which we conducted with each participant individually. Then we organized a collective interview with a few participants six months later to cross check our findings. The individual interviews included eight questions each, which allowed us to start the conversations. The eight questions are listed below:

1. Why is the incubator regulated at the level of $5 \% \mathrm{CO}_{2}$ ?

2. Have you heard this question before?

3. Do you think that this question has been trivialized or neglected?

4. Do other biology labs in Belgium and elsewhere also regulate their incubators at $5 \% \mathrm{CO}_{2}$ ?

5. Do you think that this question is important for your research?

6. Is $5 \%$ of $\mathrm{CO}_{2}$ the same condition in the human body?

7. How true this is: "“incubators are regulated at $5 \% \mathrm{CO}_{2}$ because that is how the desired pH level can be maintained"”?

8. What other negative consequences can happen to the cells, due to this $5 \%$ level?

Depending on the participant's accounts in each question, we asked further questions. The different interview questions were designed to invite the participants to account for the following central issue: Does the 5\% level of $\mathrm{CO}_{2}$ have negative consequences on research? The collective interview, which also included the same eight questions as the first interviews, was less structured because the participants anticipated many questions. Nonetheless, we made sure that we went through all of them to get as much data as possible to analyze.

\section{Findings}

Through the analysis of the case study and the collected data, this study identifies three major findings. The first finding is that the lab participants had never discussed why they were using $5 \%$ of $\mathrm{CO}_{2}$ in their daily cell culture operations. The field researcher's questions on a trivialized matter triggered internal discussions and constructed organizational knowledge. Through field observation and question \#2 of the individual interviews: "have you heard this question before?" the participants realized that they were experiencing groupthink by not challenging a piece of scientific information.

The lab scientists were surprised by our questions and were initially not able to provide answers (saying typically: "I don't know," "it's a shame that we don't have an answer"). At the same time, the participants said that the use of this level is extremely important and that they should not change it by any means. Later in discussions (during observation), the participants figured out more or less the same answer to our question: that the 5\% is important for the $\mathrm{pH}$ regulation. With further detailed discussions, we found that the different lab members' responses were quite variant and sometimes contradictory. Likewise, accounts of the same person were sometimes inconsistent.

During the individual interviews, new ideas emerged out of the detailed discussions; and participants shifted positions several times. All participants said that the $5 \%$ level is a standard (or a norm) that is accepted worldwide, but all of them have accounted for the negative consequences of this standardization. They said that it might potentially skew any of their experiments, which they do on cells that do not require $5 \%$ of $\mathrm{CO}_{2}$. They mentioned the following skews: "phenotype change," "shifting from in vivo model," and "blinding."

The second finding is that the use of the $5 \%$ level was a seen but unnoticed practice (Garfinkel, 2002) and that our question, which aligns with Garfinkel 1967's strategy of breaching experiment, triggered unprecedented discussions. Hence, more and more detrivializing accounts emerged and gained ground. Additionally, we found that one postdoctoral researcher had -to the surprise of her colleagues- used $10 \%$ in one of her previous labs, although all the participants said that any level other than $5 \%$ would not be acceptable; because it would change the cells' $\mathrm{pH}$, and therefore skew their experiments. The postdoctoral researcher said that she does not know why this lab is using $5 \%$, although she said that she already knows that this level is a worldwide standard. 
The third finding is that the origin of the standard of $5 \%$ was not known. Instead, the lab director concluded during the interview that it was initially dictated commercially and did not emanate from research. The lab director also said that the providers who were first able to produce a medium with a pH of 7.4 (which was solicited by research) dictated the level of $5 \%$ of $\mathrm{CO}_{2}$. Hence, the $5 \%$ level is successful in reaching a $\mathrm{pH}$ of 7.4 , but its drawbacks for other considerations are at least according to our participants not known. They have never been discussed within the scope of cancer researchers.

In line with Latour and Woolgar (1979), several non-scientific accounts were used to justify scientific positions: a) defending the need to standardize the level of $5 \%$, even after saying that the level can skew research and that it needs to be revised depending on the requirements of the cell; b) justifying the $5 \%$ level by the need to replicate the same research by another lab, even after we pointed out many times that labs that are interested in replicating their experiment can do so by following the research protocol with whatever level it mentions and not necessarily $5 \%$.

Finally, some participants realized after openly discussing the matter that they are using the $5 \%$ level even for cells that do not need a pH of 7.4, but rather 6.5. Some participants said that a $5 \%$ level was appropriate for any desired $\mathrm{pH}$ level, whereas others assured that the $5 \%$ is specifically for the cells that need a $\mathrm{pH}$ of 7.4. Because the lab uses the same incubators (regulated at $5 \%$ by default) for all types of cells (those that need a $\mathrm{pH}$ of 7.4 , 6.5 , etc.), the participants who said that $5 \%$ is only suitable for a $\mathrm{pH} 7.4$, clarified that they add buffers to cells that require $6.5 \mathrm{pH}$. When they referred to buffers, all participants added or implied that the buffers' negative consequences are not trivial and that they would need to reconsider how to reach the desired $\mathrm{pH}$ level, not through the $5 \%$ level of $\mathrm{CO}_{2}$. The next section discusses the study's contribution to suggest detrivialization as a method of examining how trivialized matters could construct organizational knowledge.

\section{Discussion}

In the present study's analysis, we aim to distinguish between scientific facts of weak rhetoric as opposed to scientific facts of strong rhetoric. The former is rather a well-established truth that scientists are unable to justify, especially when they state that they have never thought of or known why it was so. Also, we consider a scientific truth to be of persuasive rhetoric, when scientists account for its origin and can justify its usefulness, in a somewhat consistent way. Our conception of scientific knowledge is rather constructionist; no matter how strong the scientists' justification is, we still consider scientific facts to be contingent and highly sociological in nature (Callon, 1986). The latter author conducted a field study to identify elements and factors that played a major role in the decision making of scientific matters. Non-human elements and factors played a major role in trivialized organizational decisions that people see as scientific, rational, and well thought.

As discussed in the paper's introduction, to trivialize is to consider that the matter is not important. In contrast, detrivialize is a neologism that we are suggesting in this study to explain the change in one's mind when something trivialized turns out to be important. The use of the word "(de)trivialize" is referring to the oscillation between the two positions: trivialization and detrivialization. Concerning the individual detrivialization practices, some participants already started with some degree of detrivializing accounts during the synchronic interviews and increased their detrivialization, during the focused discussions. Other participants (one of them stepped back from his accounts that he made before the interviews) started by trivializing the negative consequences of the standardization of the $\mathrm{CO}_{2}$ level and ended the interview by detrivializing it, mentioning the possible skews. The lab director detrivialized the issue, all along with the interview, justifying his accounts with details of the potential skews. Still, suddenly at the very end of the interview, he concluded with ungrounded trivializing accounts that the skews are "minimal."

We also found that when we pointed out a contradiction between two accounts or a problem regarding a particular practice, the participants responded to our comments, reframing the dissonance or trivializing the importance of the problem. Discursive tools were used: 1) Switching from the first personal pronouns "we" and "I" (also their equivalents "nous" and "je" in French) to the second personal pronouns "you" or sometimes "people" (also "tu" and "des gens" in French). While the use of "we" (and equivalents) referred to practices that emphasize that things are under control, the use of the inclusive "you" referred to weaknesses implying "you too would do what we're doing," or to practices that are hypothetical rather than confirmed to have been implemented; 2) Using "also," "sometimes," and "it depends" to connect two incongruent ideas and to minimize the contradiction. Finally, we found that some participants used the "yes but no" while others used the "no but 
yes" strategies. 3) "Yes but no" consisted of agreeing on everything and admitting all the weaknesses of a particular practice but disagreeing (at the very end of the interview) with the idea that the discussed practice should be revised, without backing up such a position. 4) "No but yes" consisted of disagreeing and challenging all critiques to the practice, but agreeing that the practice should be revised.

During the collective interviews, the participants started by trivializing the consequences of the standardization of the $5 \%$ level. They initially made short and unproblematic answers, as if we have never discussed the complexity before. Furthermore, they did not contradict each other even though they had already made contradictory accounts during the individual interviews. Only when we pointed out the contradictions that we found after analyzing the individual interviews did the participants start to account for the negative consequences of the standardization of the $\mathrm{CO}_{2}$ level. The same skew risks emanating from the standardization, which were accounted for during the individual interviews, were then again accounted for during the collective interview.

Finally, the participants did not stick to one position, but rather restlessly oscillated between opposite positions. When they detrivialize the negative outcome of the standardization, they provide justifications (i.e. "phenotype change," "shift from in vivo model," and "blinding"), but when they trivialize it, they mention two reasons: 1) that they need to standardize, to align with oncology research practices worldwide, without detailing the advantage of such an alignment; and 2) that other labs if they want to replicate any of this labs' experiments, they will do it using 5\%. Furthermore, we found that the participants avoided on many occasions to respond to the following two questions, regarding the two reasons they mentioned: 1) why do you need to standardize a condition that you say that it may skew your experiments? And 2) if other labs are interested in replicating your experiment, why don't they use the level that you would anyway mention in your research protocol and which you would decide to be suitable to your type of cells? The next section concludes by suggesting detrivialization as a strategy of challenging organizational groupthink.

\section{Conclusions}

A major concern of the present research was to reflect on how organizational knowledge is constructed by studying detrivialization. Could detrivialization function as a strategy of challenging organizational groupthink? The case study reveals that almost all lab members said that they had never thought about such issues before. The study discusses groupthink as an organizational dynamic that affects people's knowing activities and perhaps puts organizational communication capacities at stake. This paper highlights the role of ethnomethodology and discourse analysis in understanding aspects of organizational knowledge construction. Also, the paper concludes that groupthink is an organizational communication dynamic that is responsible for knowledge construction on two levels.

The first level of groupthink resonates with what Foucault (1969) identifies as "a microphysical power." Groupthink is a hidden and unnoticeable dynamic that could construct organizational knowledge on the background (Hallgren, 2010). More precisely, the detrivialization of this issue emanated from the problematization of what participants call: a) the existing knowledge, b) the standards, c) the practical knowledge, and d) the previous validation. This underlying power could also be explained by the robustness of the "structure" (Giddens, 1984) and its supremacy over the "agency." The participants were defending the "structure" when they embodied it against their knowing freedom- "agency."

The second level is illustrated through the dynamic of knowledge automatization when participants were visibly aiming at converging, conforming, and agreeing, particularly during the diachronic interview. This dynamic is similar to Janis (1982)'s groupthink, which occurs in various organizations. Groupthink causes individuals not to be able to dare to ask new questions or to practice their knowing activity genuinely (Janis, 1982). This study argues that groupthink occurs when people feel that they might destabilize the group's harmony and homogeneity by not challenging trivialized matters.

Studying this case of detrivialization from a discursive psychological point of view enabled us to zoom in and out between the following three levels that come into play concerning how knowledge is constructed: 1) the (inter)organizational level; 2) the individual level, and 3) the group level. The study suggests a three-level organizational interaction model to explore groupthink as an organizational dynamic responsible for knowledge construction. 
1. The Organizational Level

Our first question was confronted by a long-established trivialization that is rather an organizational default condition or tradition (structural), a standard of unknown origin, than an individually-motivated or an explicit group decision. Nonetheless, the same trivializations were, to some extent, group and individual practices. No matter how 'passive' or inadvertent these practices are, they are, to some extent, choices made by the participants (researchers) during the design of their research protocols. Before our breaching experimental questions (Garfinkel, 1967), the trivializations were unnoticeable conditions and taken for granted practices. The moment our questions came up to the surface, the trivialization started to be noticed. Noticing the longestablished trivialization and especially what underlies it in terms of consequences for their research was the first spark of detrivialization.

2. The Individual Level

During the individual interviews, participants were invited to reflect and account for the previously (personally but less formally) discussed issues. Right from the beginning of the interviews, we made it clear that accounts such as "this or that condition is a standard" would not suffice, by responding "what is the rationale of this standard?" Similarly, if the participants say, "this is an existing knowledge," we would respond, "why do you need it? Or how useful is it for your research"? Consequently, the individual participant embodied the whole lab and sometimes the whole research domain, because he or she needed to explain the rationale of the research practices, for which they are not directly or personally responsible.

This study illustrated how participants restlessly oscillated between two stances: the "cozy but imprisoning structure" and the "free but uncomfortable agency." Individually, they tend to say that they are following a standardized process, which is beyond their control, and that applies to the whole domain. But when they fail to justify or explain the situation, they do not identify with it (the standardized process) and would prefer to move to another position, where they are free to criticize the status quo. And once individuals are settled in new positions, they would notice that in reality, much of their previous research was done differently, which makes this new position equally uncomfortable. The oscillation between the two positions was less frequent than in the diachronic and collective interview but was equally related to the contradiction that we pointed out.

3. The Group Level

The diachronic and collective interviews were conducted about six months after the last individual interview. The participants knew in advance that the interviews were going to be about the same questions that we discussed individually during the synchronic interviews. No matter how divergent their accounts and positions were during the individual interviews, they dramatically converged during the collective interviews. The result was that participants collectively and recurrently oscillated between two opposite positions, in five steps:

1. participants start by selecting and playing up a single aspect that demonstrates the accuracy of their practice (under discussion);

2. researchers point out another aspect that participants ignored or played down unintentionally (based on what some of them mentioned in the individual interviews to be of greater importance);

3. participants account for the negative aspect of the trivialized practice and consequently detrivialize the issue;

4. participants change their original point of view and reach a new conclusion (participants do not expect to reach consensus as individuals might insist that this is a matter of personal judgment);

5. researchers step back to adopt a detrivializing position to bring up the previous argument and seek for new justifications regarding the discussed practice. Hence, the oscillation between steps one to five was visibly recurrent and reflected the restless state of the group.

Figure 1 - (de)trivialization dynamic model- depicts the existing trivialization that preceded our present study and the detrivilization provoked by this research, at the three levels described in this section. 


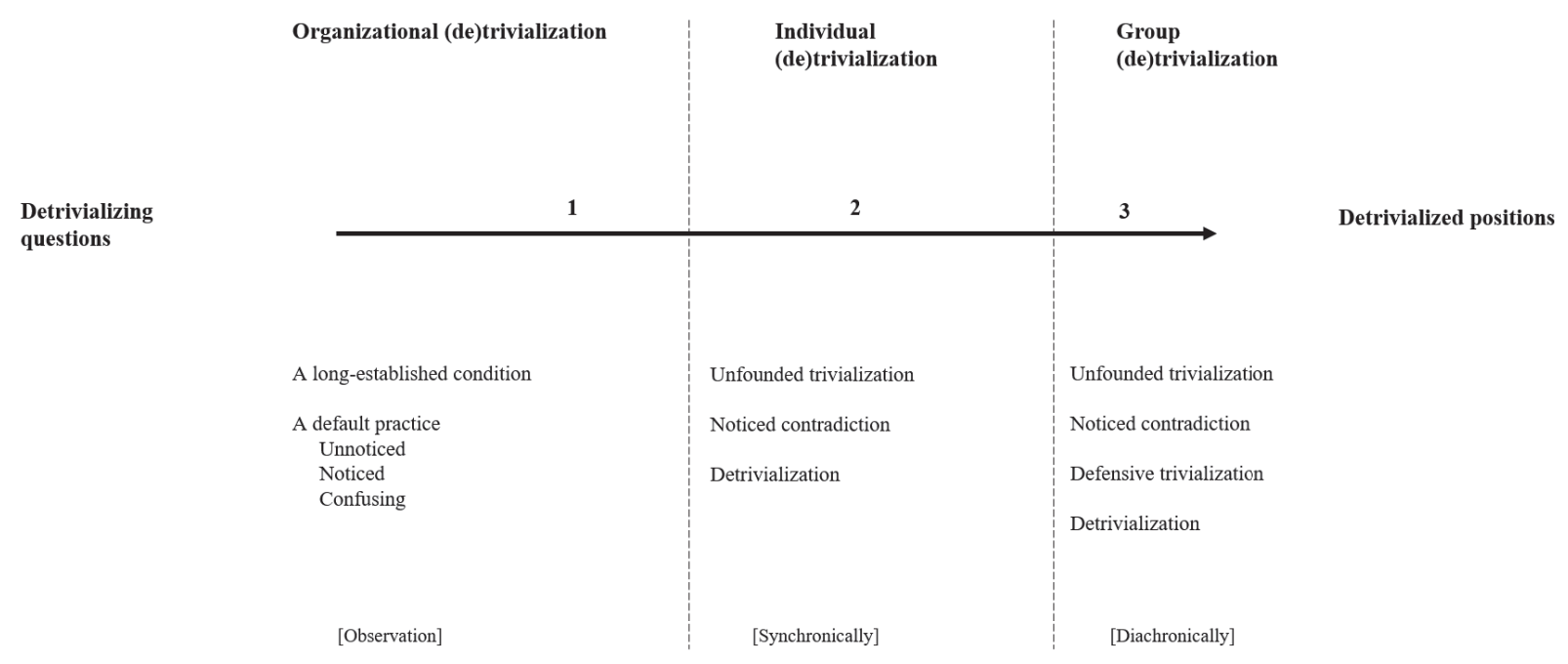

Figure 1: The (de)trivialization dynamic model

The (de)trivialization dynamic model portrays this paper's suggestion for exploring trivialization. The model exposes what our detrivializing questions faced at three levels: a) the (inter)-organizational level (as a longestablished condition or practice within this lab but also in almost every cancer research lab in the world); b) the individual level (how our participants responded to our questions, individually); and c) the group level (how our participants conducted themselves during the collective interview).

Organizations could study participants' knowledge bases through a series of detrivializing questions and interviews, as suggested by the present study. This paper concludes that regardless of people's level of education, organizational culture is more potent than the individual's knowing capacity. The periodic application of detrivialization as a strategy to challenge groupthink and construct knowledge could apply in various organizations.

\section{References}

Beebe, S. and Masterson, J.T., 2014. Communicating in small groups, 11th Edition, Essex, UK: Pearson Education Limited. Ben-Hur, S., Kinley, N. and Jonsen, K., 2012. Coaching executive teams to reach better decisions, Journal of Management Development, [online] 31(7), pp.711-723. Available at: https://doi.org/10.1108/02621711211243908 [Accessed 15 Jan. 2020].

Callon, M., 1986. Some elements of a sociology of translation: domestication of the scallops and the fishermen of St Brieuc Bay. In: J.Law (ed.), Power, Action and Belief: A New Sociology of Knowledge. London: Routledge \& Kegan Paul.

Carlson, G.S., 2016. Groupthink. In: G. Mazzoleni (ed.), The International Encyclopedia of Political Communication, [online]. Available at: < doi:10.1002/9781118541555.wbiepc026> [Accessed 15 Jan. 2020].

Eaton, J., 2001. Management communication: the threat of groupthink, Corporate Communications: An International Journal, [online] 6(4), pp.183-192.https://doi.org/10.1108/13563280110409791 [Accessed 15 Jan. 2020].

Eisenberg, E., Goodall, H.L. and Trethewey, A., 2010. Organizational Communication. Bedford: St. Martin's.

Erdem, F., 2003. Optimal trust and teamwork: from groupthink to teamthink, Work Study, [online] 52(5), pp.229-233. Available at: <https://doi.org/10.1108/00438020310485958> [Accessed 15 Jan. 2020].

Evans, M.M., Frissen, L.A, and Choo, C.W., 2019. The strength of trust over ties: investigating the relationships between trustworthiness and tie-strength ineffective knowledge sharing, Electronic Journal of Knowledge Management, [online] 17(1), pp.19-33 Available at: <https://issuu.com/academic-conferences.org/docs/ejkm-volume17-issue1article866? mode $=a$ p $>$ [Accessed 15 Jan. 2020].

Festinger, L., 1962. Cognitive dissonance. Scientific American, 207(4), pp.93-107.

Feyerabend, P., 1978. Science in a free society. London: New Left Books.

Foucault, M., 1969. The archaeology of knowledge. Translated by A M Sheridan Smith. London and New York: Routledge. Garfinkel, H., 1967. Studies in enthnomethodology. Englewood Cliffs, NJ: Prentice-Hall.

Garfinkel, H., 2002. Ethnomethodology's Program: Working Out Durkheim's Aphorism. Lanham, MD: Rowman \& Littlefield. Giddens, A., 1984. The constitution of society: Outline of the theory of structuration. Cambridge: Polity Press.

Hällgren, M., 2010. Groupthink in temporary organizations, International Journal of Managing Projects in Business, 3(1), pp.94-110.

Janis, I. L., 1971. Groupthink. Psychology Today, 5(6), pp.43-46.

Janis, I. L., 1982. Groupthink (2nd ed.). Boston: Houghton Mifflin. 
Koerber, C. and Neck, C., 2003. Groupthink and sports: an application of Whyte's model, International Journal of Contemporary Hospitality Management, [online] 15(1), pp.20-28. Available at: <https://doi.org/10.1108/09596110310458954> [Accessed 15 Jan. 2020].

Kroon, M., Hart, P. and van Kreveld, D., 1991. Managing group decision making process: Individual versus collective accountability and groupthink, International Journal of Conflict Management, [online] 2(2), pp.91-115. Available at: <https://doi.org/10.1108/eb022695> [Accessed 10 Jan. 2020].

Kucharska, W. Bedford, D., 2019. Knowledge sharing and organizational culture dimensions: Does job satisfaction matter? Electronic Journal of Knowledge Management, [online] 17(1), pp.118. Available at: <http://dx.doi.org/10.2139/ssrn.3406496> [Accessed 15 Jan. 2020].

Kuhn, T., 2014. Knowledge and knowing in organizational communication. In: L. L. Putnam and D.

K. Mumby, Handbook of Organizational Communication $3^{\text {rd }}$ ed. pp.481-502.

Kyakulumbye, S. Pather, S. Jantjies, M., 2019. Knowledge creation in a participatory design context: the use of empathetic participatory design, Electronic Journal of Knowledge Management, [online] 17(1), pp.49-65. Available at:

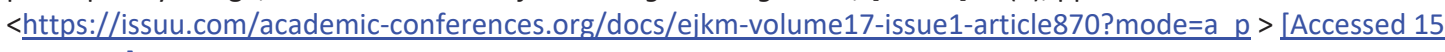
Jan. 2020].

Latour, B., 1987. Science in action: How to follow scientists and engineers through society. Milton Keynes: Open University Press.

Latour, B., 2005. Reassembling the social: An introduction to actor-network theory. Oxford: Oxford University Press.

Latour, B., and Woolgar, S., 1979. Laboratory Life: The Construction of Scientific Facts. Princeton University Press.

Mpeera Ntayi, J., Byabashaija, W., Eyaa, S., Ngoma, M. and Muliira, A. (2010). Social cohesion, groupthink and ethical behavior of public procurement officers, Journal of Public Procurement, [online] 10(1), pp.68-92. Available at: <https://doi.org/10.1108/JOPP-10-01-2010-B003> [Accessed 16 Jan. 2020].

Oxford Dictionaries, 2018. Trivial. [online]. Available at: <http://www.oxforddictionaries.com/definition/american_english/trivial?q=TRIVIAL> [Accessed on 27 Dec. 2019].

Parkinson, C. N., 1958. Parkinson's law, or the pursuit of progress. London: John Murray.

Potter, J. and Wetherell, M., 1987. Discourse and social psychology: Beyond attitudes and behaviour. London: Sage.

Sai On Ko, A., 2005. Organizational communications in Hong Kong: a cultural approach to groupthink, Corporate Communications: An International Journal, [online] 10(4), pp.351-357. Available at: <https://doi.org/10.1108/13563280510630142> [Accessed 15 Jan. 2020].

Simon, L., Greenberg, J., and Brehm, J., 1995. Trivialization: the forgotten mode of dissonance reduction. Journal of Personality and Social Psychology, 68, pp.247-260.

Whyte, G., 1989. Groupthink reconsidered. Academy of Management Review, 14 (1), pp. 40-56.

Whyte, G., 1952. Groupthink. Fortune, March, pp.114-117. 